\title{
Electronic nicotine delivery systems (e-cigarettes) as a smoking cessation aid: a survey among pharmacy staff in Queensland, Australia
}

Daniel A Erku ${ }^{1,2^{*}}$, Coral E Gartner ${ }^{3}$, Jennifer Thi Do ${ }^{1}$, Kylie Morphett ${ }^{3}$, and Kathryn J Steadman ${ }^{1}$

${ }^{1}$ School of Pharmacy, The University of Queensland, 20 Cornwall Street, Woolloongabba 4102, Queensland, Australia

${ }^{2}$ School of Pharmacy, College of Medicine and Health Sciences, University of Gondar, Ethiopia

${ }^{3}$ School of Public Health, The University of Queensland, Herston Road, Herston 4006, Queensland, Australia

\section{Email addresses:}

Daniel A Erku: d.erku@uq.edu.au

Coral Gartner: c.gartner@uq.edu.au

Jennifer Thi Do: thi.do7@uqconnect.edu.au

Kylie Morphett: k.morphett@uq.edu.au

Kathryn Steadman: k.steadman@uq.edu.au

*Corresponding author

Postal address: School of Pharmacy, The University of Queensland, Pharmacy Australia Centre of Excellence, 20 Cornwall Street, Woolloongabba QLD 4102, Australia 


\begin{abstract}
Objectives: This study examined views of pharmacy staff regarding the safety of e-cigarettes compared to nicotine replacement therapies (NRTs) and conventional cigarettes, as well as views on their regulation in Australia.

Methods: We conducted a cross-sectional survey among pharmacy staff (64 pharmacists and 76 pharmacy assistants) from the greater Brisbane region, Queensland, Australia. The selfadministered questionnaire included closed- and open-ended questions that explores pharmacy staff perception on harms of e-cigarettes versus NRT and traditional cigarettes, knowledge of current e-cigarette regulations, views on how they should be regulated and information needs regarding e-cigarettes. Pearson's chi-square test was employed for computing differences between variables. A content analysis of responses to open-ended questions was also performed.
\end{abstract}

Results: Over $90 \%$ of pharmacy staff regarded e-cigarettes without nicotine and NRTs as less harmful than regular tobacco cigarettes. This reduced to $72 \%$ for e-cigarettes containing nicotine, with $24 \%$ of respondents believing they are equally as harmful as conventional cigarettes. Moreover, few respondents were confident about the short and long term safety of e-cigarettes containing nicotine (36\% and $15 \%$ respectively) whereas pharmacy staff were more comfortable with the safety of NRTs for short $(88 \%)$ and long term $(35 \%)$ use. The majority of respondents believed that e-cigarettes with nicotine should be regulated as a medicine, either requiring a prescription (24\%) or sold only by pharmacies (22\%), though many believed that they should be regulated in the same way as regular tobacco cigarettes $(27 \%)$. Some pharmacy staff (39\%) reported having been asked about e-cigarettes by customers and $75 \%$ believed that their customers would be interested in using e-cigarettes as a smoking cessation aid.

Conclusions: There is a need to provide evidence-based and customised education for pharmacists regarding e-cigarettes to help them guide their clients.

Key words: Electronic cigarettes, ENDS, Community pharmacist, Australia 


\section{Introduction}

Being located at the heart of the community and widely distributed geographically, community pharmacies provide a unique platform to deliver proactive public health services such as smoking cessation support (1). A recent systematic review and meta-analysis that examined the impact of community pharmacy-led smoking cessation interventions concluded that pharmacist-led behavioural support together with the use of nicotine replacement therapies (NRTs) leads to a higher quit rate compared to unassisted quit attempts or standard cessation advice plus NRTs (2). Although smoking cessation advice and approved pharmacological smoking cessation aids including varenicline, bupropion and a range of NRTs (3) (4) are widely available in high income countries, such as Australia, an increasing number of smokers are using electronic nicotine delivery systems, or e-cigarettes, as a cessation aid or lower risk alternative to conventional cigarettes $(5,6)$.

According to a national survey conducted by the Australian Institute of Health and Welfare in 2016, the use of e-cigarettes in Australia significantly increased between 2013 and 2016, with approximately one third of smokers (31\%) having ever tried e-cigarettes and $4.4 \%$ currently using them (7). However, the role of e-cigarettes in quitting smoking is strongly debated (8). In the UK, there is a growing consensus among medical and public health organisations and societies that encouraging smokers to switch to e-cigarettes will produce population health gains (9). Conversely, similar organisations in other countries and some global agencies including the World Federation of Public Health Associations (10) and the World Medical Association (11) endorsed the report commissioned by World Health Organization (WHO), that described the current scientific evidence regarding e-cigarettes as "scant and of low certainty, making it difficult to draw credible inferences." The WHO also promotes banning all forms of advertising and promotion of e-cigarettes, prohibiting unproven health claims and extending smoke-free policies to include vaping (12).

Due to being a relatively new product, the risks of long-term use of e-cigarettes are uncertain. Public Health England (PHE) issued an updated report in early 2018 that reaffirmed its previous estimate that e-cigarettes are about 95\% safer than conventional cigarettes (13). While there is an ongoing debate about the accuracy of this estimate, a consensus report from the National Academies of Sciences, Engineering, and Medicine, concluded that "there is conclusive evidence that completely substituting e-cigarettes for combustible tobacco 
cigarettes reduces users' exposure to numerous toxicants and carcinogens present in combustible tobacco cigarettes" and "there is substantial evidence that completely switching from regular use of combustible tobacco cigarettes to e-cigarettes results in reduced shortterm adverse health outcomes in several organ systems" (14). Despite these reports, there is a growing body of literature that suggests that the general public hold misperceptions about the relative harms of e-cigarettes, with many considering them to be as harmful as tobacco cigarettes $(13,15)$.

Among smokers, the likelihood of switching from smoking to vaping appears to be associated with harm perceptions. A longitudinal study showed that those who perceived e-cigarettes as less harmful were more likely to subsequently try them (16). Although many smokers perceive e-cigarettes to be less risky than conventional cigarettes $(17,18)$ a considerable proportion of smokers report that they do not know whether e-cigarettes are safer than tobacco cigarettes, or believe they are just as harmful (19). Many smokers report being interested in receiving information about the safety of e-cigarettes (20). Together, these findings suggest a need for clear and evidence-based information on the relative harm of ecigarettes and combustible tobacco products. Healthcare professionals are uniquely positioned to provide such information to smokers and the general public. However, little attention has been given to how healthcare professionals perceive e-cigarettes (21). A survey conducted among healthcare professionals in Greece reported that while about 33\% of respondents recommend e-cigarettes to smokers, $40 \%$ of respondents were reluctant to recommend these products to smokers, including for those who are unable or unwilling to quit by any other means (22). Similarly, in a recent cross-sectional survey conducted among community pharmacists in London, it was reported that $42 \%$ of respondents expressed safety concerns regarding excipients of e-cigarettes and $88 \%$ of them indicated the need for training and workshops about e-cigarettes (23).

The regulatory framework regarding e-cigarettes varies considerably between countries. The laws and policies in most countries were developed based on existing tobacco or nicotine product regulations or through amending the tobacco control laws (24). In 2014, the European Parliament passed the EU Tobacco Product Directive (TPD) that suggested a series of policy domains for regulating e-cigarettes in terms of sale, product safety, packaging, advertising, taxation and restricting vaping in public spaces (25). By the end of 2016, the EU- 
TPD provisions were transposed into national policies and implemented by the UK and 14 EU member countries (out of 24 countries) $(26,27)$. In the United States, the Food and Drug Administration (FDA) recently took responsibility of regulation of e-cigarettes as "tobacco products" with respect to manufacturing standards, sale, advertising and product packaging (28). Similarly, in New Zealand, the government recently proposed a new regulatory option, via amending the Smoke-free Environments Act 1990, to allow the sale and supply of ecigarettes and e-liquid containing nicotine as consumer products, while maintaining medicines regulation for e-cigarette products that claim therapeutic benefits. The amendment bill will also heavily restrict access to e-cigarettes by people under the age of 18 years and prohibit vaping in smoke-free areas (29).

In Australia, current regulations governing e-cigarettes and personal vaporizers are complex and encompass tobacco control, poisons regulation, therapeutic goods, and consumer protection legislation (30). Nicotine is classified by Australia's Therapeutic Goods Administration (TGA) as a dangerous poison (Schedule 7) except when used in approved smoking cessation products or for other human therapeutic use, but there are no e-cigarettes listed on the Australian Register of Therapeutic Goods (31). Therefore, while approved NRT products can be purchased from a range of commercial outlets including supermarkets and petrol stations, e-cigarettes containing nicotine are illegal to sell (30). However, according to the TGA, Australians can access nicotine for use in e-cigarettes for a therapeutic purpose (e.g. quitting smoking) via one of the legal pathways for accessing unapproved therapeutic goods, if the person holds a valid medical prescription from a medical practitioner registered in Australia. This includes personal importation, the Special Access Scheme, Authorised Prescriber Scheme and extemporaneous compounding $(32,33)$. The extent to which pharmacy staff are aware of these regulations in Australia is currently unknown. The aim of the present survey was to assess the opinions of pharmacy staff regarding the use and safety of e-cigarettes as a smoking cessation aid, as well as knowledge of current regulations and attitudes toward how they should be regulated.

\section{Methods}

A survey of pharmacy staff was conducted in 2015. Both pharmacists and pharmacy assistants were invited to participate. Pharmacists were defined as holding a minimum qualification of a bachelor's degree in pharmacy and a valid licence to practice pharmacy. 
Pharmacy assistants were defined as having completed a recognized training or certificate courses relevant to their role which includes supplying pharmacy only medicines under a pharmacist's supervision, supplying some over-the-counter medicines and other administration duties (34). The self-administered questionnaire consisted of closed- and open-ended questions that explored: perceptions of the safety of e-cigarettes as a smoking cessation aid; as well as their views on how e-cigarettes are, and should be, regulated in Australia. Ethical approval was obtained from the University of Queensland, School of Pharmacy Ethics Committee. Participants were given an information sheet explaining the aim of the survey, confirming the anonymity of the data and provided the contact details of the investigators. Informed consent from all participants was obtained before commencing data collection.

A member of the research team (TD) visited a convenience sample of pharmacies within a 30 $\mathrm{km}$ radius of the central business district of Brisbane, Queensland. We recruited different types of pharmacy premises (independent and banner group) and located in different settings (e.g. shopping centre, medical centre or strip mall). All pharmacy staff were approached in person, and were given the option to complete and return the questionnaire in the presence of the data collector or to complete and leave for collection the following day. The questionnaire was created by modifying items in a previously used data collection tool (23), and items were reviewed by the research team which included an experienced pharmacy practice researcher and a public health expert. The final data collection tool were then pilot-tested with selected pharmacists for understanding. The final questionnaire consisted of 20 questions that included multiple response (Likert scale), closed (Yes/No) and open-ended questions measuring i) perceptions of the safety of NRTs and e-cigarettes and the relative harmfulness of e-cigarettes, NRTs and other tobacco products compared to regular tobacco cigarettes; ii) knowledge of current Queensland regulations concerning nicotine and non-nicotine ecigarette products; iii) views on how they should be regulated and iv) information needs regarding e-cigarettes. Finally, respondents were asked for demographic characteristics including age, gender, role in the pharmacy, ever use of tobacco products and e-cigarettes.

\subsection{Data analysis}

The data were entered into and analysed using Statistical Package for the Social Sciences (SPSS) software version 25.0 for Windows (SPSS Inc., Chicago, IL). Categorical data were 
described using frequencies and percentages. Pearson's chi-square test was employed for computing differences between pharmacists and pharmacy technicians. A $p$-value of less than 0.05 was considered statistically significant. A content analysis of responses to open-ended questions was also performed.

\section{Results}

\subsection{Demographic characteristics}

Staff from 55 of the 58 pharmacies approached participated in the survey. The pharmacies that participated in the survey represent $20 \%$ of all community pharmacies located within a $30 \mathrm{~km}$ radius of Brisbane city centre. These pharmacies were distributed across 31 out of a total of 83 postal codes that fall in that area. A total of $64(45.7 \%)$ pharmacists (including 6 pharmacy interns) and 76 (53.3\%) pharmacy assistants completed the survey (Table 1). Most participants had never smoked tobacco $(85 \%)$ or tried e-cigarettes $(88 \%)$.

All of the pharmacies stocked and recommended a wide range of NRT products. The most frequently ("most of the time" or "always") recommended types of NRTs were nicotine patches $(61 \%)$, nicotine gum $(47 \%)$ and nicotine lozenges $(28 \%)$. None of the participating pharmacies stocked or sold e-cigarettes.

Table 1. Participant characteristics according to their pharmacy role

\begin{tabular}{|c|c|c|c|c|c|c|}
\hline \multirow[t]{2}{*}{ Variable } & \multicolumn{2}{|c|}{$\begin{array}{c}\text { Total } \\
\text { n=140 }\end{array}$} & \multicolumn{2}{|c|}{$\begin{array}{c}\text { Pharmacists } \\
n=64\end{array}$} & \multicolumn{2}{|c|}{$\begin{array}{c}\text { Pharmacy assistants } \\
n=76\end{array}$} \\
\hline & $\mathbf{n}$ & $(\%)$ & $\mathbf{n}$ & $(\%)$ & $\mathbf{n}$ & $(\%)$ \\
\hline \multicolumn{7}{|l|}{ Gender } \\
\hline Male & 37 & (26.3) & 27 & $(42.2)$ & 10 & (13.1) \\
\hline Female & 103 & (73.7) & 37 & $(57.8)$ & 66 & $(86.8)$ \\
\hline \multicolumn{7}{|l|}{ Age } \\
\hline $16-25$ & 72 & (51.4) & 26 & $(40.6)$ & 46 & $(60.5)$ \\
\hline $26-35$ & 39 & (27.9) & 25 & $(39.1)$ & 14 & (18.4) \\
\hline $35+$ & 29 & (20.7) & 13 & (20.3) & 16 & (21) \\
\hline
\end{tabular}

Smoking status $(n=139)$ 


$\begin{array}{lrlrlrl}\text { Never smoked } & 119 & (85.6) & 59 & (92.2) & 60 & (88.9) \\ \text { Ex-smoker } & 14 & (9.4) & 5 & (7.8) & 9 & (11.8) \\ \text { Current smoker } & 7 & (5.0) & 0 & (0) & 7 & (9.2)\end{array}$

\section{Ever tried e-cigarettes}

$\begin{array}{lrlrlrl}\text { No } & 123 & (87.8) & 57 & (89.1) & 65 & (85.5) \\ \text { Yes, with nicotine } & 5 & (3.6) & 3 & (4.7) & 2 & (2.6) \\ \text { Yes, without nicotine } & 12 & (8.6) & 4 & (6.2) & 8 & (10.5)\end{array}$

The majority of participants in this survey were female (74\%). Most of the males that took part were pharmacists, leading to a significant difference $(\mathrm{p}<0.05)$ in gender between pharmacists and pharmacy assistants. There were no other differences in baseline characteristics. Similarly, no significant difference was found in responses to all safety and regulation questions between qualifications (pharmacist vs pharmacy assistant), age, smoking status and ever use of e-cigarettes. Therefore all data is presented as a mean across all of the respondents without further subdivision.

Compared to regular tobacco cigarettes, most participants (94\%) rated NRTs as less harmful than regular tobacco cigarettes, though $6 \%$ believed that NRTs are equally as harmful (Figure 1). A similar proportion regarded e-cigarettes without nicotine to be less harmful than tobacco cigarettes, however fewer $(72 \%)$ believed that nicotine-containing e-cigarettes are less harmful, while $24 \%$ believed they are equally as harmful, and $4 \%$ thought they are more harmful than tobacco cigarettes. Responses regarding relative safety of nicotine-containing ecigarettes were similar to opinions on the relative safety of nicotine-free herbal cigarettes (Figure 1). More people disagreed (39\%) than agreed (14\%) with the statement that ecigarettes are safer than NRTs but most answered 'neither agree nor disagree' which may indicate that they consider them to be similar in terms of safety or that they didn't have an opinion or knowledge (Table 2). 


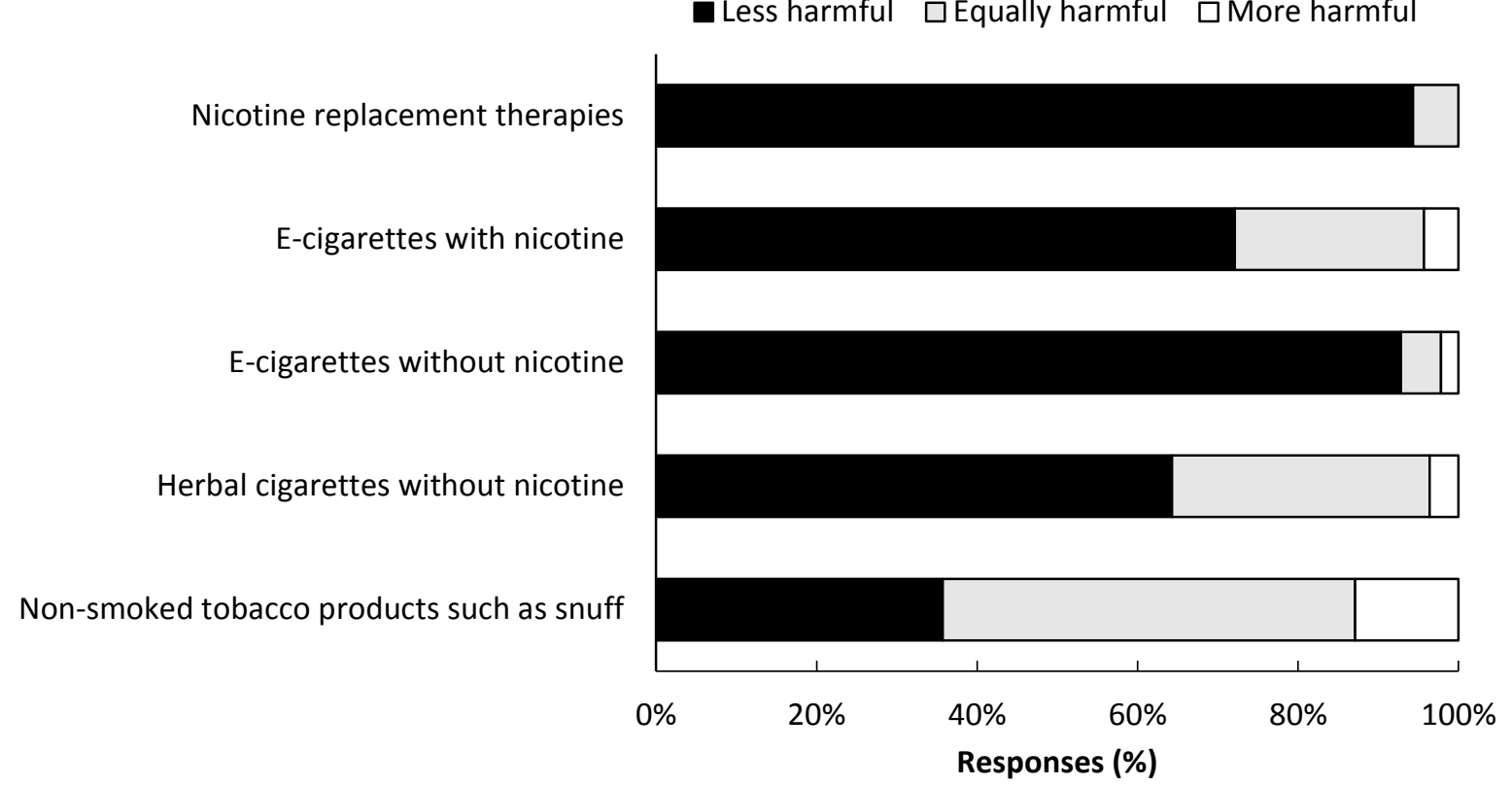

Figure 1. Perceived safety of nicotine replacement therapy (NRT) products, e-cigarettes and other tobacco products compared to regular tobacco cigarettes. Responses were much less / a little less harmful (black bars), equally harmful (grey bars) and much more / a little more harmful (white bars) than tobacco cigarettes.

The majority of respondents (88\%) agreed/strongly agreed that NRTs are safe for short term use. However, this dropped to $35 \%$ agreeing/strongly agreeing with NRTs being safe for long term use (Table 2). Respondents were much less confident about the safety of e-cigarettes, as $36 \%$ agreed/strongly agreed that short term use of e-cigarettes would be safe, and only $15 \%$ indicated that long term use would be safe. Pharmacy staff were mostly negative (57-61\%) regarding the safety of both NRT and e-cigarettes for lifetime use (Table 2).

Table 2. Respondent opinions about the safety of NRTs and e-cigarettes containing nicotine.

\begin{tabular}{cccc}
\hline Variables & Disagree/strongl & Neither & Agree/strongl \\
y disagree & agree nor & y agree \\
& disagree & \\
& $\mathbf{n}(\%)$ & $\mathbf{n}(\%)$ & $\mathbf{n}(\%)$ \\
\hline
\end{tabular}


Safe to use for short term ( $<6$ months)

$\begin{array}{lrlrrrr}\text { NRTs }(\mathrm{n}=139) & 3 & (2.2) & 14 & (10.1) & 122 & (87.8) \\ \text { E-cigarettes }(\mathrm{n}=138) & 30 & (21.7) & 59 & (42.7) & 49 & (35.6)\end{array}$

Safe to use for long term (few years)

$\begin{array}{lllllll}\text { NRTs }(\mathrm{n}=140) & 42 & (30.0) & 49 & (35.0) & 49 & (35.0) \\ \text { E-cigarettes }(\mathrm{n}=138) & 65 & (47.1) & 53 & (38.4) & 20 & (14.5)\end{array}$

Safe to use for lifetime

$\begin{array}{llllllll}\text { NRTs }(\mathrm{n}=140) & 85 & (60.7) & 36 & (25.7) & 19 & (13.6) \\ \text { E-cigarettes }(\mathrm{n}=138) & 78 & (56.5) & 49 & (35.5) & 11 & (8.0) \\ \text { arettes are safer than NRTs } & 54 & (39.1) & 65 & (47.1) & 19 & (13.8) \\ 38) & & & & & & \end{array}$

Half of participants in this study answered "don't know" on how e-cigarettes with nicotine $(43.6 \%)$ and without nicotine $(51.4 \%)$ or nicotine e-liquid $(55 \%)$ are regulated (Table 3$)$. The remainder were split between believing that it is illegal versus legal to sell in Queensland. Very few considered that any of these products could be obtained through a pharmacy. However, $46 \%$ of pharmacy staff held the opinion that e-cigarettes with nicotine and nicotine e-liquid should be available through pharmacies, split evenly between whether this should be with or without a prescription. Conversely, many were of the opinion that nicotine-containing e-cigarettes $(27 \%)$ and nicotine liquid for use in refillable vaporisers (22\%) should be regulated in the same way as regular tobacco cigarettes. Without nicotine, opinions were fairly evenly split between regulating in the same way as tobacco cigarettes (29\%), sale through a pharmacy without a prescription (28\%), and no regulation being necessary (20\%).

Table 3. Pharmacy staff knowledge on current regulations regarding e-cigarettes, and opinions on how e-cigarettes should be regulated.

\begin{tabular}{cccc}
\hline Statements & $\begin{array}{c}\text { Nicotine } \\
\text { solution* }\end{array}$ & $\begin{array}{c}\text { E-cigarettes } \\
\text { with nicotine }\end{array}$ & $\begin{array}{c}\text { E-cigarettes } \\
\text { without } \\
\text { nicotine }\end{array}$ \\
\cline { 2 - 4 } & $\mathrm{n}(\%)$ & $\mathbf{n}(\%)$ & $\mathbf{n}(\%)$ \\
\hline
\end{tabular}


How are sales of electronic cigarettes currently regulated in Queensland?

No regulation - can be sold by anyone to

$21 \quad(15.0)$

$17 \quad(12.1)$

$35 \quad(25.0)$

anyone

Same as tobacco cigarettes

9 (6.4)

18 (12.9)

$13 \quad(9.3)$

As pharmacy or pharmacist only products**

5 (3.6)

$1 \quad(0.7)$

5 (3.6)

Require a prescription

2 (1.4)

$1 \quad(0.7)$

$0 \quad(0)$

Illegal to sell

42 (30.0)

15 (10.7)

Don't know

$77 \quad(55.0)$

$61 \quad(43.6)$

72 (51.4)

How do you think sales of electronic cigarettes should be regulated in Queensland?

No regulation - can be sold by anyone to

$6 \quad(4.3)$

5 (3.6)

28 (20)

anyone

Same as tobacco cigarettes

38 (27.1)

$41 \quad(29.3)$

As pharmacy or pharmacist only products**

31 (22.1)

Require a prescription

$30 \quad(21.4)$

33 (23.6)

$10 \quad(7.1)$

Illegal to sell

11 (7.9)

15 (10.7)

3 (2.1)

Don't know

28 (20)

18 (12.9)

19 (13.6)

* For use in a refillable tank style electronic vaporizer

** Medicines belonging to the Australian SUSMP Schedules 2 or 3. S2: Pharmacy medicine, S3: Pharmacist only medicine

According to the survey, 39\% of pharmacy staff had been asked about e-cigarettes by their customers and $75 \%$ of pharmacy staff believed that their customers would be interested in using e-cigarettes as a smoking cessation aid. The majority of respondents (91\%) believed that pharmacy staff need more information regarding e-cigarettes. Free text responses to an item asking about information needs in relation to e-cigarettes were provided by 75 respondents. The most common response was to identify a lack of knowledge, formal education or an absence of guidelines about e-cigarettes (39\%). It was also common for pharmacy staff to identify a need to educate or counsel customers and to provide recommendations for or against use (33\%). Some free-text responses noted increasing enquiries about e-cigarettes from customers (8\%), and others thought that e-cigarettes could potentially help smokers quit $(8 \%)$. 


\section{Discussion}

With the growing popularity and use of e-cigarettes as a way to quit smoking, it is essential that pharmacists have adequate and updated information in order to guide their customers in making evidence-based decisions. This is the first survey in Australia to examine the views of pharmacy staff toward the use of e-cigarettes as a smoking cessation aid, their perception of safety relative to cigarettes and NRTs, and knowledge and attitudes toward their regulation.

In many countries, sale of e-cigarettes in pharmacies is common. In countries where tobacco products are sold in pharmacies, such as the USA, it is unsurprising that e-cigarettes are also sold because they are treated as if they are tobacco products (35). None of the pharmacies in this survey reported stocking e-cigarettes. The Pharmacy Board of Australia states that the sale of tobacco products is regarded as unprofessional conduct, but has not provided advice on the sale of e-cigarettes (36). Similar to Australia, tobacco products are not sold in UK pharmacies, however, in contrast to Australia, most sell e-cigarettes and professional bodies have positions and policies in regard to e-cigarettes. The Royal Pharmaceutical Society (RPS) in the UK indicate in their position statement that "where someone is unwilling to use a licensed NRT product, pharmacists should use their professional judgement when giving advice to patients and the public on the use of e-cigarettes" (37). The General Pharmaceutical Council (GPhC) also state that "The health, safety and well-being of patients must be the first concern for pharmacy owners and superintendents when deciding which products and services to supply in a pharmacy" (38). A study conducted in London reported that $73 \%$ of community pharmacies surveyed sold e-cigarettes, and more than two thirds of the pharmacists perceived e-cigarettes as being as safe and effective as NRTs (23). Disappointingly, a recent review of business compliance conducted by Trading Standards Services in England reported that $53 \%$ of independent pharmacies and $43 \%$ of chain pharmacies illegally sold e-cigarettes to minors (under 18 years old) (39).

More than two thirds of respondents in our study believed that e-cigarettes (with or without nicotine) were less harmful than regular tobacco cigarettes. However, $28 \%$ viewed ecigarettes containing nicotine to be more harmful than or as harmful as tobacco cigarettes. Nicotine is a psychoactive substance responsible for addictive/craving symptoms and associated with mild cardiotoxicity (40), but most of the toxicants responsible for cancer and cardiovascular diseases are associated with combustion of tobacco and are absent from e- 
cigarette vapour or present in much lower quantities, which makes them a lower risk alternative to combustible cigarettes. This notion is supported by recent consensus report issued by the US National Academies of Science, Engineering and Medicine, which stated that completely replacing regular tobacco cigarettes by e-cigarettes reduces exposure to many toxicants and carcinogens (14). The updated PHE report also stated that e-cigarettes are about 95\% safer than conventional cigarettes and concluded that the cancer risk of e-cigarettes were lower than the risk of smoking combustible cigarettes (13). Both reports acknowledge the need for continued research on the short and long term safety of these products.

Currently, regulation of e-cigarettes in Australia is confusing, and interpretations and application of current laws have varied across different jurisdictions. Tobacco intended for smoking is the only non-therapeutic nicotine product for human use that is exempt from the classification as a dangerous poison in Australia (30). The TGA have clarified that ecigarettes containing nicotine can be legally accessed for therapeutic purposes (e.g. quitting smoking) using a number of pathways for accessing unapproved therapeutic goods, including personal importation, the Special Access Scheme, Authorised Prescriber Scheme and extemporaneous compounding (32). All of these require a valid prescription from a medical practitioner registered in Australia, and direct-to-consumer advertising is not permitted for prescription medicines in Australia. However, the law has been interpreted differently by Queensland Health (the State Government Health Department), who have stated in a factsheet on e-cigarettes that "these products, once imported, are classified as a poison, not a therapeutic good" (41). In a magazine produced for pharmacy owners in Australia (42), the Pharmacy Guild of Australia stated that promoting, stocking, and/or supplying of e-cigarettes in pharmacies as a smoking cessation aid is against its Quality Care Pharmacy Program (QCPP) requirements (43), which indicates that cigarettes, tobacco or smoking-related products or implements should not be sold or promoted. However, there are no clear guidelines or policy statements provided by any of the professional organisations for pharmacists on how Australian pharmacy staff should handle customer enquiries about ecigarettes or on dispensing prescriptions for nicotine solution for use in e-cigarettes as a cessation aid.

The Australian Department of Health has acknowledged there is public confusion about the legal status of e-cigarettes "especially in terms of the regulations that apply to their 
importation, marketing (including sale) and use" (44). This confusion was reflected in our findings with pharmacy staff. There was no common understanding of current regulation of e-cigarettes in Australia, and a large proportion of participants reported that they did not know how e-cigarettes or nicotine liquid were regulated. In addition, there was no consensus among pharmacy staff on how e-cigarettes (with or without nicotine) should be regulated. Around $45 \%$ of the pharmacy staff in the present study considered that e-cigarettes containing nicotine should be regulated in such a way as to allow them to be available through a pharmacy, with half of those advising that availability should require a prescription. If e-cigarettes are to be regulated as "pharmacy only" or "prescription only" products, pharmacy staff would need to be more aware and have better understanding of these products. Yet others believed that they should be regulated in the same way as regular tobacco cigarettes (which are not sold in pharmacies in Australia). A similar lack of consensus was observed in terms of regulating nicotine free e-cigarettes and nicotine e-liquid.

In our study, $39 \%$ of pharmacy staff reported being asked about e-cigarettes by their customers and approximately two thirds of pharmacy staff thought that their customers would be interested in using e-cigarettes as a smoking cessation aid. This is comparable to the $35 \%$ of U.S. and Canadian quit line counsellors and $48 \%$ of physicians in North Carolina who reported being asked about e-cigarettes by their clients $(45,46)$. The majority of pharmacy staff $(91 \%)$ in our study indicated that they need more information regarding e-cigarettes. As a trusted source of health information, smokers are likely to consult community pharmacists for evidence-based advice about e-cigarettes. Clinical practice guidelines have been published and provide evidence-based information regarding e-cigarettes for healthcare professionals involved in adolescent health (47), otolaryngologists (48), cardiologists (49) and nurses (50). Recently, UK's National Centre for Smoking Cessation and Training has published an online training for health professionals regarding e-cigarettes and smoking cessation (51). Yet, there is lack of such practice guidelines for pharmacists in Australia.

The present survey highlights an area of research where there is lack of literature in Australia. This study has a number of methodological limitations that should be taken into consideration while interpreting the findings. Firstly, the survey used for assessing the perception of pharmacy staff regarding electronic cigarettes had not been previously validated. Although we did not perform preliminary interviews which could elicit concepts and inform our survey 
contents, we developed the survey items based on an extensive literature review. We also included additional free text options, allowing us to further elicit new themes. Additionally, as the study focussed only on a convenience sample of pharmacy staff and employed a descriptive cross-sectional study design, caution should be exercised when generalizing to other regions and territories in Australia. Nonetheless, this survey provides valuable insight into the existing gap in awareness of e-cigarette product characteristics and its potential impact on public health.

\section{Conclusions}

This survey was conducted in order to gain an insight into the perceptions of pharmacy staff regarding e-cigarettes in terms of safety, regulations and information and training needs. The majority of pharmacy staff believed that e-cigarettes are safe for short term use and perceived e-cigarettes as less harmful compared to regular tobacco cigarettes. Our results also suggest that consumers expect pharmacy staff to be aware of these products as the participants in our study reported receiving client inquiries about e-cigarettes. Thus, evidence-based and customised educational intervention (such as a practice guideline) for pharmacists about ecigarettes would be useful. However, the inconsistency in interpretation of the law by state and federal regulators needs to be resolved so that pharmacy staff and the public have confidence in their legal responsibilities. 


\section{References}

1. Saba M, Diep J, Saini B, Dhippayom T. Meta-analysis of the effectiveness of smoking cessation interventions in community pharmacy. J Clin Pharm Ther. 2014;39(3):240-7.

2. Brown TJ, Todd A, O'Malley C, Moore HJ, Husband AK, Bambra C, et al. Community pharmacy-delivered interventions for public health priorities: a systematic review of interventions for alcohol reduction, smoking cessation and weight management, including meta-analysis for smoking cessation. BMJ open. 2016;6(2):e009828.

3. Costello MJ, Sproule B, Victor JC, Leatherdale ST, Zawertailo L, Selby P. Effectiveness of pharmacist counseling combined with nicotine replacement therapy: a pragmatic randomized trial with 6,987 smokers. Cancer Causes Control. 2011;22(2):167-80.

4. Aubin HJ, Luquiens A, Berlin I. Pharmacotherapy for smoking cessation: pharmacological principles and clinical practice. Br J Clin Pharmacol. 2014;77(2):324-36.

5. Pepper JK, Brewer NT. Electronic nicotine delivery system (electronic cigarette) awareness, use, reactions and beliefs: a systematic review. Tob Control. 2014;23(5):375-84.

6. Yoong SL, Stockings E, Chai LK, Tzelepis F, Wiggers J, Oldmeadow C, et al. Prevalence of electronic nicotine delivery systems (ENDS) use among youth globally: a systematic review and meta-analysis of country level data. Aust N Z J Public Health. 2018.

7. Australia Institute of Health and Welfare. National Drug Strategy Household Survey detailed report 20162016 [Available from: https://www.aihw.gov.au/reports/illicit-use-of-drugs/2016-ndshsdetailed/contents/table-of-contents.

8. Glynn TJ. E-cigarettes and the future of tobacco control. CA Cancer J Clin. 2014;64(3):164-8.

9. Britton J. Electronic cigarettes and smoking cessation in England. BMJ. 2016;354.

10. World Federation of Public Health Associations. Statement by the World Federation of Public Health Associations on electronic cigarettes. Geneva: World Federation of Public Health Associations,; 2015 [Available from: http://www.wfpha.org/publications/news/128-statement-bythe-wfpha-on-electronic-cigarettes.

11. World Medical Association. Statement on electronic cigarettes and other electronic nicotine delivery systems. Geneva: World Medical Association; 2012 [Available from:

https://www.wma.net/policies-post/wma-statement-on-electronic-cigarettes-and-other-electronicnicotine-delivery-systems/.

12. World Health Organization. Electronic nicotine delivery systems and electronic non-nicotine delivery systems: World Health Organization,; 2016 [Available from: http://www.who.int/fctc/cop/cop7/FCTC_COP_7_11_EN.pdf?ua=1.

13. McNeill A, Brose LS, Calder R, Bauld L, Robson D. Evidence review of e-cigarettes and heated tobacco products 2018: Public Health England; 2018 [Available from: 
https://www.gov.uk/government/publications/e-cigarettes-and-heated-tobacco-products-evidencereview/evidence-review-of-e-cigarettes-and-heated-tobacco-products-2018-executive-summary. 14. National Academies of Science EaM. Public Health Consequences of E-Cigarettes 2018 [Available from: http://nationalacademies.org/hmd/Reports/2018/public-health-consequences-of-ecigarettes.aspx.

15. Majeed BA, Weaver SR, Gregory KR, Whitney CF, Slovic P, Pechacek TF, et al. Changing perceptions of harm of e-cigarettes among US adults, 2012-2015. Am J Prev Med. 2017;52(3):331-8. 16. Brose LS, Brown J, Hitchman SC, McNeill A. Perceived relative harm of electronic cigarettes over time and impact on subsequent use. A survey with 1-year and 2-year follow-ups. Drug Alcohol Depend. 2015;157:106-11.

17. Goniewicz ML, Lingas EO, Hajek P. Patterns of electronic cigarette use and user beliefs about their safety and benefits: an internet survey. Drug and alcohol review. 2013;32(2):133-40.

18. Wackowski OA, Delnevo CD. Young adults' risk perceptions of various tobacco products relative to cigarettes: results from the National Young Adult Health Survey. Health Educ Behav. 2016;43(3):328-36.

19. Yong H-H, Borland R, Balmford J, Hitchman SC, Cummings KM, Driezen P, et al. Prevalence and correlates of the belief that electronic cigarettes are a lot less harmful than conventional cigarettes under the different regulatory environments of Australia and the United Kingdom. Nicotine \& Tobacco Research. 2017;19(2):258-63.

20. Wackowski OA, Manderski MTB, Delnevo CD. Smokers' sources of e-cigarette awareness and risk information. Preventive medicine reports. 2015;2:906-10.

21. Erku DA GCE, Morphett Kylie, Steadman Kathryn J,. Beliefs and self-practices of healthcare professionals regarding electronic nicotine delivery systems (ENDS): a systematic review [in press]. Addiction. 2018.

22. Moysidou A, Farsalinos KE, Voudris V, Merakou K, Kourea K, Barbouni A. Knowledge and perceptions about nicotine, nicotine replacement therapies and electronic cigarettes among healthcare professionals in Greece. Int J Environ Res Public Health. 2016;13(5):514.

23. Gomes ACM, Nabhani-Gebara S, Kayyali R, Buonocore F, Calabrese G. Survey of community pharmacists' perception of electronic cigarettes in London. BMJ open. 2016;6(11):e013214.

24. Institute for Global Tobacco Control. Country laws regulating e-cigarettes: A policy scan: John Hopkins Bloomberg School of Public Health; 2015 [Available from:

https://www.globaltobaccocontrol.org/e-cigarette/country-laws-regulating-e-cigarettes.

25. European Commission. Revision of the tobacco products directive. 2014 [Available from: https://ec.europa.eu/health/tobacco/products/revision_en.

26. The National Archives. Tobacco and Related Products Regulations 2016 [Available from: http://www.legislation.gov.uk/uksi/2016/507/contents/made.

27. Awopegba A KR, and Cohen J,. Approaches to Transposing the European Union Tobacco Products Directive E-cigarette Rules into Legislation by European Union Member States: Johns Hopkins Bloomberg School of Public Health; 2017 [Available from:

https://www.jhsph.edu/research/centers-and-institutes/institute-for-global-tobaccocontrol/_pdfs/posters-and-presentations/2017/SRNT\%20Awopegba\%20E-cigarette\%20Scan.pdf. 28. Food and Drug Administration. 81 Federal Register 28973 (21 CFR Parts 1100, 1140, 1143: Government Publishing Office: FDA; 2016 [Available from: https://www.gpo.gov/fdsys/pkg/FR-201605-10/pdf/2016-10685.pdf.

29. The New Zealand Parliament. Smoke-free Environments (Regulation of Electronic Cigarettes) Amendment Bill. 20182018 [Available from: https://www.parliament.nz/resource/enNZ/52HOH_MEMBILL086_1/10b7e820ce38c3be7035d92f55f922c7f3c75ade.

30. Douglas H, Hall W, Gartner C. E-cigarettes and the law in Australia. Aust Fam Physician. 2015;44(6):415. 
31. Therapeutic Goods Administration. Poisons Standard March 2018. Federal Register of Legislation 2018 [Available from: https://www.legislation.gov.au/Details/F2018L00168.

32. Therapeutic Goods Administration (TGA). Inquiry into the Use and Marketing of Electronic Cigarettes and Personal Vaporisers in Australia Submission 297 - Supplementary Submission 12017 [Available from:

https://www.aph.gov.au/Parliamentary_Business/Committees/House/Health_Aged_Care_and_Spor t/ElectronicCigarettes/Submissions.

33. Therapeutic Goods Administration. Liquid nicotine and personal importation for use in electronic cigarettes. Canberra: TGA; 2014 [Available from: https://www.tga.gov.au/behindnews/liquid-nicotine-and-personal-importation-use-electronic-cigarettes\#.U7o-O8hiuDQ.

34. Moles RJ, Stehlik P. Pharmacy practice in Australia. The Canadian journal of hospital pharmacy. 2015;68(5):418.

35. Rose SW, Barker DC, D'angelo H, Khan T, Huang J, Chaloupka FJ, et al. The availability of electronic cigarettes in US retail outlets, 2012: results of two national studies. Tob Control. 2014;23(suppl 3):iii10-iii6.

36. Pharmacy Board of Australia. Guidelines on practice-specific issues. 2015 [Available from: http://www.pharmacyboard.gov.au/Codes-Guidelines.aspx.

37. Royal Pharmaceutical Society. E-cigarettes position statement 2016 [Available from: https://www.rpharms.com/making-a-difference/policy-a-z/e-cigarettes.

38. General Pharmaceutical Councel (GPhC). GPhC outlines position on sale of e-cigarettes in registered pharmacies. 2014 [Available from: https://www.pharmacyregulation.org/gphc-outlinesposition-sale-e-cigarettes-registered-pharmacies.

39. Chartered Trading Standards Institute. A review of business compliance with the Nicotine Inhaling Products (Age of Sale and Proxy Purchasing) Regulations 2015 [Available from:

https://www.tradingstandards.uk/news-policy/news-room/2016/study-shows-four-in-ten-retailersflout-laws-on-nicotine-inhaling-products.

40. Benowitz NL, Burbank AD. Cardiovascular toxicity of nicotine: implications for electronic cigarette use. Trends Cardiovasc Med. 2016;26(6):515-23.

41. Queensland Government. Electronic Cigarettes - The Facts. 2017 [Available from: https://www.frasercoastchronicle.com.au/news/hervey-bay-authorities-cracking-down-illegal-ecig/2180697/ or http://media2.apnonline.com.au/img/media/pdf/e-cig1-9n8trp3w0idn42dsph2.pdf and http://media2.apnonline.com.au/img/media/pdf/e-cig2-6k7fssqsrnz1jndsph2.pdf.

42. Pharmacy guild of Australia. Pharmacy guild of Australia Excellence winter 2015. 2015 [Available from:

https://www.guild.org.au/_data/assets/pdf_file/0018/5274/excellence_winter2015_web.pdf 43. Revised Quality Care Pharmacy Program (QCPP) Requirements 2017 [Available from: http://www.qcpp.com/resources/qcpp-in-practice/qcpp-in-practice/2017/06/05/revised-qcpprequirements.

44. The Department of Health. Principles that Underpin the Current Policy and Regulatory Approach to Electronic Cigarettes (E-Cigarettes) in Australia. 2018 [Available from:

http://www.health.gov.au/internet/main/publishing.nsf/Content/principles-underpin-currentpolicy-regulatory-approach-electroniccigarettes-eeCigarettes-australia.

45. Cummins S, Leischow S, Bailey L, Bush T, Wassum K, Copeland L, et al. Knowledge and beliefs about electronic cigarettes among quitline cessation staff. Addict Behav. 2016;60:78-83.

46. Kandra KL, Ranney LM, Lee JG, Goldstein AO. Physicians' attitudes and use of e-cigarettes as cessation devices, North Carolina, 2013. PLoS One. 2014;9(7):e103462.

47. Hildick-Smith GJ, Pesko MF, Shearer L, Hughes JM, Chang J, Loughlin GM, et al. A practitioner's guide to electronic cigarettes in the adolescent population. J Adolesc Health. 2015;57(6):574-9. 
48. Biyani S, Derkay CS. E-cigarettes: an update on considerations for the otolaryngologist. Int J Pediatr Otorhinolaryngol. 2017;94:14-6.

49. Liberman J, Wann S. E-Cigarettes-What a Practicing Cardiologist Needs to Know. Am J Cardiol. 2017;119(4):681-6.

50. Prochnow JA. E-cigarettes: A Practical, Evidence-based Guide for Advanced Practice Nurses. The Journal for Nurse Practitioners. 2017;13(7):449-55.

51. National Centre for Smoking Cessation and Training. E-cigarettes: a guide for healthcare professionals. 2018 [Available from: http://elearning.ncsct.co.uk/e cigarettes-stage 1. 


\section{Author disclosure}

\section{Funding}

DAE was supported by University of Queensland (UQ) Research and Training Scholarship. No other financial support was gained to conduct this study.

\section{Contributors}

DAE conducted literature searches, performed analysis, interpreted data and wrote the first draft of the manuscript. JTD contributed to the design of the study and collected the data. KJS, and CEG designed and supervised the project. KJS, CEG and KM contributed to the analysis of the results and to the writing of the manuscript. All the authors have read and approved the final manuscript.

\section{Conflict of Interest}

All authors declare that there is no actual or potential conflict of interest. CG is a chief investigator on a number of research projects examining the effectiveness of vaping as a smoking cessation method which are funded by NHMRC, HIV Foundation Queensland, and VicHealth. She has received paid travel and accommodation from Wellmark to present at the HIV Innovation Forum 2017, which was sponsored by an unrestricted educational grant from Gilead Sciences. 


\section{Highlights}

Staff regarded e-cigarettes without nicotine as less harmful than tobacco cigarettes.

Pharmacy staff believed that e-cigarettes with nicotine should be regulated as a medicine.

Some pharmacy staff reported having been asked about e-cigarettes by customers

Majority of staff indicated the need for more information regarding e-cigarettes 